\title{
Investigating the Relationship Between Financial Stress Index and MENA Stock Markets Performance
}

\author{
Hayet Soltani $^{1, ~ *}$, Mouna Boujelbene Abbes ${ }^{1}$, Abderrahmen Aloulou ${ }^{2}$ \\ ${ }^{1}$ Faculty of Economics and Management of Sfax, Economic and Management Laboratory (LEG), University of Sfax, Sfax, Tunisia \\ ${ }^{2}$ Graduate School of Business, Economic and Management Laboratory (LEG), University of Sfax, Sfax, Tunisia
}

\section{Email address}

hayetsoltani91@yahoo.fr (H. Soltani), abbes.mouna@gmail.com (M. B. Abbes), aloulou.abderrahmen@gmail.com (A. Aloulou)

${ }^{*}$ Corresponding author

\section{To cite this article:}

Hayet Soltani, Mouna Boujelbene Abbes, Abderrahmen Aloulou. Investigating the Relationship Between Financial Stress Index and MENA Stock Markets Performance. International Journal of Finance and Banking Research. Vol. 7, No. 5, 2021, pp. 111-122. doi: $10.11648 / j . i j f b r .20210705 .12$

Received: July 16, 2021; Accepted: September 15, 2021; Published: September 27, 2021

\begin{abstract}
This article assesses the effect of financial stress caused by the great depression, 2008-2009, Oil crises of 20142015 accompanied by the sharp fall in the oil prices and the Arab Spring on the co-movements and volatility spillovers of aggregated Financial Stress Indices for eleven MENA countries. It is reveals that the extreme values of the FSIs are generally connected with well-known past financial stress episodes. We also found, for MENA Ex GCC countries, a weak interconnection between these countries while the GCC countries are more connected. Using a Vector auto-regression (VAR) estimation framework, we showed that the performance of the stock indices depends positively on its past and also, the stress index positively depends on his past delayed either by one or two periods. While, the study of impulse response functions shows that a positive shock on the financial stress index translates into a negative effect on stock market performance during the first year. This effect then disappears in slow motion before finding its long-term level.
\end{abstract}

Keywords: Financial Stress, Financial Stress Index, Market Performance, VAR Estimation, Impulse Response Function

\section{Introduction}

Drawing a financial stress index (FSI) became imperative due to repeated incidences of financial crises. In fact, financial crises are associated with a protracted recovery from other forms of recessions [1,2].

During the recent years, an increasing number of studies have shifted concentrate to develop a financial stress indicator, which is a single composite indicator [3-6]. FSI is an alternative continuum and contemporaneous measure used to evaluate and monitor the condition of financial system considerable attempts to derive FSI for emerging countries. Balakrishnan et al. [5] not only proposes FSI for developing countries, but also consider the transmission channels of financial stress between advanced and developing countries. In fact, the FSI is constructed using the same methodology as Cardarelli et al. [7]. As well, domestic FSI of an emerging economy is pretended to be influenced by financial stress in developed economies as well as gross domestic product growth, interest rate, degree of financial and trade linkages and other domestic macroeconomics vulnerabilities [5].

From the perspective of financial stress, this investigation seeks to add to the literature by constructing a tool to quantify financial stress for some MENA countries. Furthermore, it tests its incidence on stock market performance.

The rest of this paper is organized as follows: Section 2 outlines the related literature briefly. Section 3 and Section 4 outline the variables that will be taken into account and the methodology for calculating this indicator. In section 5 we give the results followed by interpretations and section 6 conclusions.

\section{Related Literature}

In the past few years after the financial crisis broke out in the US subprime market in late of 2007, the literature on the concept of financial stress has increased rapidly. As we all know, a financial stress index quantifies the current state of 
instability in the financial system by combining multiple individual stress indicators that represent the main financial market segments (i.e. banking sector, equity, money, bond and foreign exchange markets) into a single statistic.

A large part of this body of work has concentrated on the construction of FSI for a specific country or a group of countries [8-11].

Indeed, El-Shal [12] investigates the spillover effects of the global financial crisis on the Egyptian economy by adopting the EM-FSI methodology to construct an FSI for Egypt.

Cevik et al. [6] modify and extend the EM-FSI to apply it for Bulgaria, the Czech Republic, Hungary, Poland, and Russia. Following a parallel approach, Cevik et al. [13], Dahalan et al. [10], and Tng et al. [14], create FSIs for several Asian countries. Moreover, by including indicators distinctive to the country's economy, some researchers such as Cevik et al. [9] and Ekinci [15] have established FSIs for Turkey. Duca and Peltonen [16] create the same FSI for 28 emerging and advanced countries, to identify systemic stress and assess its joint occurrence with economic downturns across their selected sample. Another example, Zigraiova and Jakubik [17] apply cross-country comparison of financial stress by constructing an FSI for 14 developing and advanced economies, including members of the European Union and OECD, in addition to others such as Argentina, Russia, and Thailand. Likewise, Duprey et al. [11] formulate a country-specific FSI for 27 European Union countries, and use it to build a monthly chronology of EU systemic financial stress episodes.

Indeed, results corroborate, from one side, that financial crises in advanced financial systems pass through to emerging markets and the degree of pass through is dependent on the depth of financial linkages among the two. From another side, Park and Mercado [18] explore the channels of financial transmission in emerging market economies. They sign through using FSI of 25 emerging markets in Asia and Europe that domestic financial stress not only increases by advanced economies FSI, but also nonregional and regional emerging market FSIs. Despite the fact of domestic financial shocks account for most of the variation in domestic FSI, regional shocks play an important role in emerging Asia [19].

As for the specific variables employed to measure financial stress, the emphasis is on banking sector, foreign exchange, debt, and equity markets, being the four most important credit channels in most countries [3, 20, 5]. Anyway, it is argued that financial markets alone is not enough to gauge financial stress of emerging markets since there are additional sources of financial stress such as external debt and sovereign risk and trade credit [21, 9].

Financial stress index is valuable not only, in evaluating macroeconomic prospects and designing monetary and fiscal policy measures. It is also useful in assessing financial conditions and fragility of the financial sector. This will also enable financial system to work steadily. Researchers take on different ways to combine indicators into an aggregate stress index. While, most investigations take the average of standardized variables, others use principal components $[3,4]$.
Cardarelli et al. [7] suggest that episodes of financial turmoil characterized by banking distress are more likely to be associated with deeper and longer downturns than episodes of stress mainly in securities or foreign exchange markets. More recently, Holló et al. [22] employed portfolio theory based aggregation schemes that take into account the correlation structure of stress indicators in order to quantify the level of systemic stress.

Furthermore, economic declines associated with bankingrelated financial stress tend to last at least twice as long as recessions which are not preceded by financial stress. Similarly, Cevik et al. [6] employ a financial stress index for Bulgaria, the Czech Republic, Hungary, Poland, and Russia. They exhibit a significant relationship between some measures of economic activity and financial stress. Islami and Kurz-Kim (2013) conclude that their FSI outperforms the Euro STOXX 50 volatility index. Their evidence suggests that the negative impact of financial stress on the real economy had a time lag of three months during the recent financial crisis and the euro-area sovereign debt crisis.

In spite of the deepening interest in exploring financial shocks through FSIs globally, there is still an uninterrupted gap for emerging countries in the literature, especially in the Middle East and North Africa that this study aims to fill.

\section{Methodology, Data and Variables}

\subsection{Data}

The dataset used to construct Financial Stress Index (FSI) is based on monthly observations retrieved from Datastream, Eikon (Thomson Reuters) and nation banks' websites over the period January 2007 to December 2018. The sample includes eleven MENA countries: Bahrain, Egypt, Jordan, Kuwait, Morocco, Oman, Qatar, Saudi Arabia, Tunisia, Turkey and the United Arab Emirates, all chosen based on data availability.

The time period is important and highly sensitive because it includes obviously significant events in which the most significant are the following: The 2007-2008 Global Financial Crisis, the beginning of the Arab Spring in January 2011 followed by the Syrian civil war since March 2011. From the second half of 2014 to January 2015 and from the fourth quarter of 2015 to January 2016, these two periods had witnessed significant drops in oil prices. Moreover, it saw the beginning of Yemeni civil war and Qatar diplomatic crisis in March 2015 and June 2017 respectively.

\subsection{Methodology and Variables}

Financial stress may be taken into account in various financial market variables. Therefore, when constructing financial stress indicators, a series of various financial market variables are usually considered. We follow a similar methodology as Balakrishnan et al [23].

We have chosen the variables presented below then to yield the aggregate financial stress index for an individual country; five components are standardized and summed up: 


$$
F S I_{E M}=\beta_{s}+\text { Stockmarketreturns }+ \text { Stockmarketvolatility }+ \text { Sovereigndebtspread }+ \text { EMPI }
$$

Where:

Beta of banking sector: This banking sector coefficient ( $\beta$ ) was introduced as an important component of the financial stress index. The usefulness of this indicator is to know the total risk associated with the banking sector. It provides us with a sector under market conditions. It can be calculated in the following manner:

$$
\beta=\frac{\operatorname{Cov}\left(r_{M}, r_{B}\right)}{\sigma^{2} M}
$$

Let: $\mathrm{r}^{\mathrm{M}}$ and $\mathrm{r}^{\mathrm{B}}$ indicate the month over month banking sector and market portfolio. $\sigma^{2} M$ represents the variance of market returns.

Stock market returns: are computed as the year-on-year change in the stock indexmultiplied by minus one.

Stock market volatility: is a time-varying measure of market volatility obtained from aGARCH $(1,1)$ specification, using month-over-month real returns and modeled as anautoregressive process with 12 lags.

Sovereign debt spreads: is defined as the bond yield minus the 10-year United States Treasury yield using JPMorgan EMBI Global spreads. When EMBI data were notavailable, five-year credit default swap spreads were used.

EMPI: mentions exchange rate depreciations and declines in international reserves, and is defined for country $i$ in month $t$ as:

$$
E M P I_{i, t}=\frac{\left(\Delta e_{i, t}-\mu_{i}, \Delta e\right)}{\left(\sigma_{i} \Delta e\right)}-\frac{\left(\Delta R E S_{i, t}-\mu_{i, \Delta R E S}\right)}{\left(\sigma_{i, \Delta R E S}\right)}
$$

Let: $\triangle \mathrm{e}$ and $\triangle R E S$ are the month-over-month percent changes in the exchange rate and total reserves minus gold, respectively. For $\mu$ and $\sigma$, they denote the mean and the standard deviation, respectively, of the relevant series.

Therefore, an aggregation of these sub-indices into a composite index is based on a variance-equal weighting approach [7, 24]. Under this method each component is computed as a deviation from its mean and weighted by the inverse of its variance [25]. This approach adjusts the stress sub-index for differences in volatility, allows a simple decomposition of stress components, and it seems also the most common weighting method in the literature.

\section{Interaction Between Financial Stress in Middle East and North Africa Countries}

\subsection{Preliminary Graphical Analysis}

Figures below plot of the aggregate financial stress index for all the series studied calculated with the variance-equal weighting method. As discussed, this is the most commonly used method in the previous study.

In a difficult international economic climate and following the outbreak of the Arab Spring, the financial systems of the MENA region have been largely affected. Great challenges are imposed on them so that they can adapt to radical changes. In this context, for MENA region, we consider the following countries: Bahrain, Egypt, Jordan, Kuwait, Morocco, Oman, Tunisia, Turkey, Qatar, Saudi Arabia and UAE.

The following figure shows the evolution of the aggregate financial stress index in the MENA region.

\section{Aggregate FSI MENA}

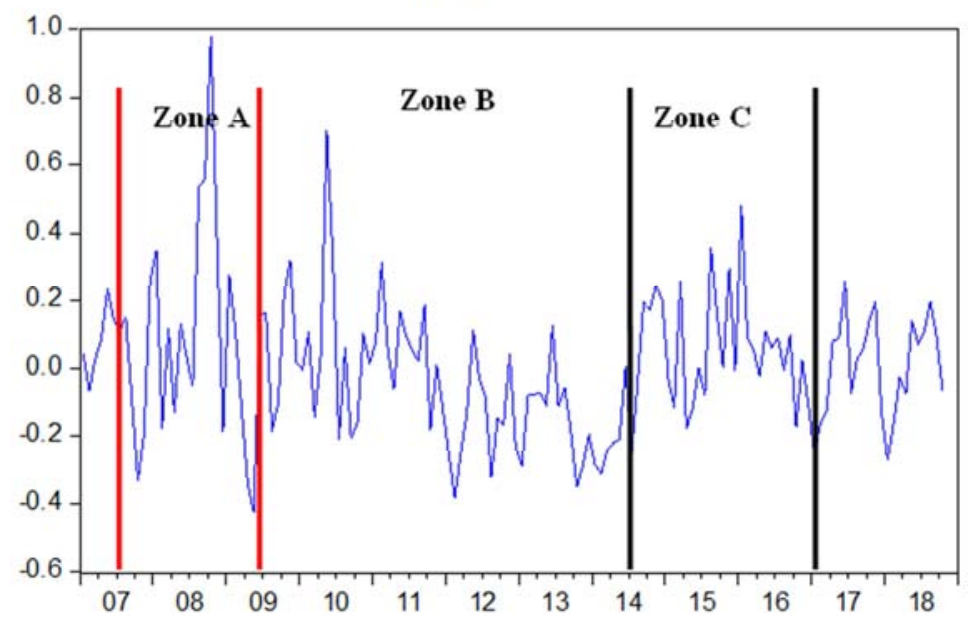

Figure 1. Aggregate FSI of MENA countries from January 2007 to December 2018.

The line graph displays the evolution of the stress associated with MENA stock markets from January 2007 to December 2018, a period that lasts almost 12 years. We can see from the graph that the level of stress associated with these markets has fluctuated from one period to the next. But the most remarkable change occurs only during the global financial crisis period (Zone A) when the majority of financial markets experience high levels of stress as well as 
during the dramatic event known as the "Arab Spring" (Zone B) and oil crisis (Zone C).

For deeper analysis, we think about a division of two groups for the studied region: the first group gathers GCC countries with big similarities and the second group reunites MENA Ex GCC countries.

\subsubsection{GCC Countries Graphical Analysis}

For GCC countries, we consider the following countries: Bahrain, Kuwait, Oman, Qatar, Saudi Arabia and United Arab Emirates. The charts below show the monthly time path of financial stress for the listed countries.

\section{FSI GCC countries}
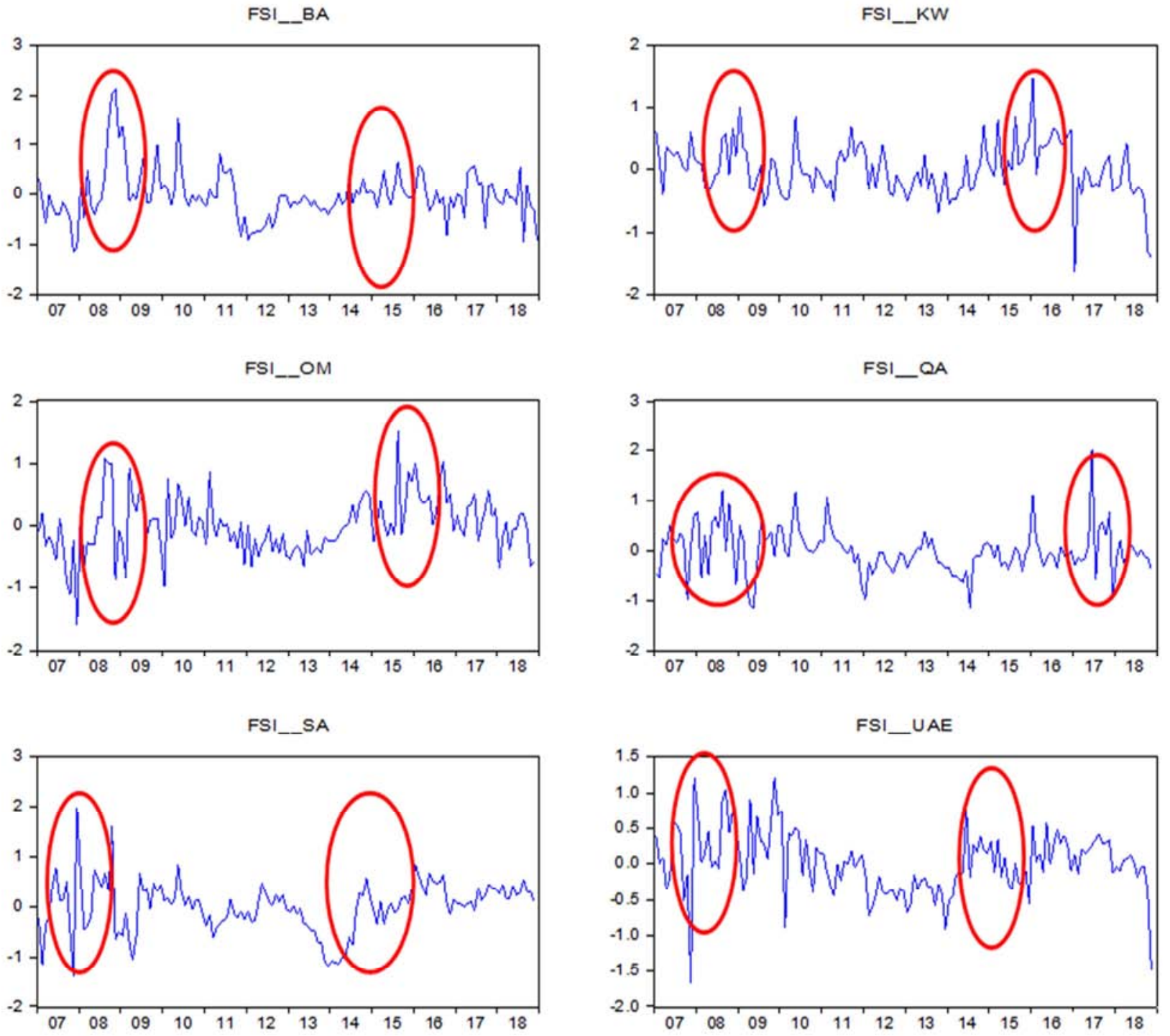

Figure 2. FSI of GCC countries from January 2007 to December 2018.

As shown in the graphs above, major periods of increasing financial stress occurred in the sample time period: during the recession of 2007-2009, when the spreads and volatilities soared in all markets. Equally, Bahraini uprising (February 14, 2011), Iran-Saudi Arabia proxy conflict called also Cold Wear (2011), Some protests in Kuwait (February 18, 2011). Moreover, the drops in the price of oil during 2014-2016 when the price of oil drops significantly, this trend continuing until 2016. Also, the 2017 political crisis among GCC members (the Qatar blockade)

Indeed, the sharp fluctuations of oil price reflect an imbalance in the oil market. Thus, world oil production is overproduced during this period, that is to say, supply exceeds demand. This fall in prices is part of a particular geopolitical and economic context: slowdown in the Chinese economy, decline in global demand, rivalry between the United States and Saudi Arabia for control of markets. Given the place of oil in the world economy and its geostrategic importance, such a fall has many consequences.

The subprime crisis (Zone $A$ ), the drop in the price of oil (Zone $B$ ) which is the backbone of the GCC countries economy and the 2017 political crisis (Zone $C$ ) are clearly reflected in the aggregated index of GCC countries. 


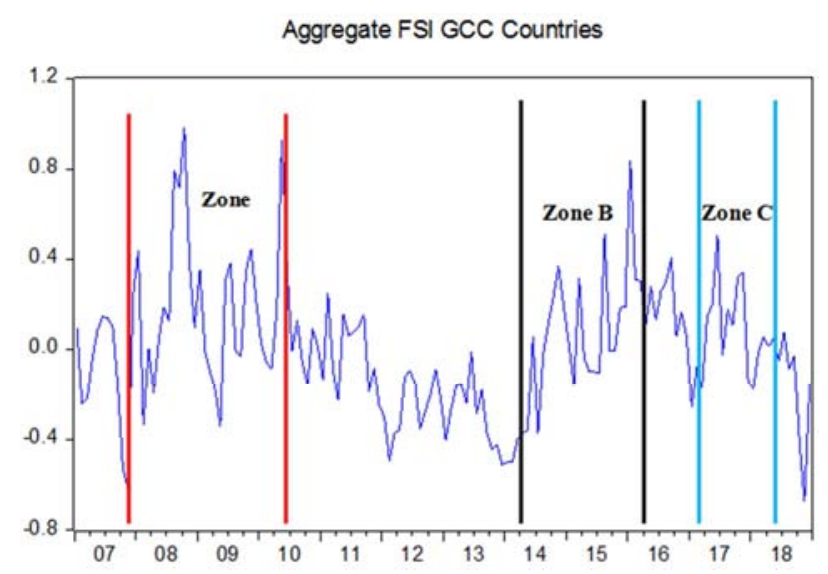

Figure 3. Aggregate FSI of GCC countries from January 2007 to December 2018.

\subsubsection{MENA EX GCC Countries Graphical Analysis}

For MENA Ex GCC countries, we consider the following countries: Egypt, Jordan, Morocco, Tunisia and Turkey.

The crisis arc in some MENA countries volume deals with the countries of the Middle East and North Africa that are facing a particularly troubled period in their historical development. Tunisia, Egypt and to a lesser extent Jordan have plunged into a legitimacy crisis that in some cases has turned into civil war or violent upheaval.

The results obtained using the FSI MENA Ex GCC countries are shown in the fourth graph. In fact, the MENA region has witnessed the political turmoil known as "Arab Revolution", which refers to a series of anti-government protests, pro-democracy uprisings and armed rebellions against existing political regimes in some MENA countries.
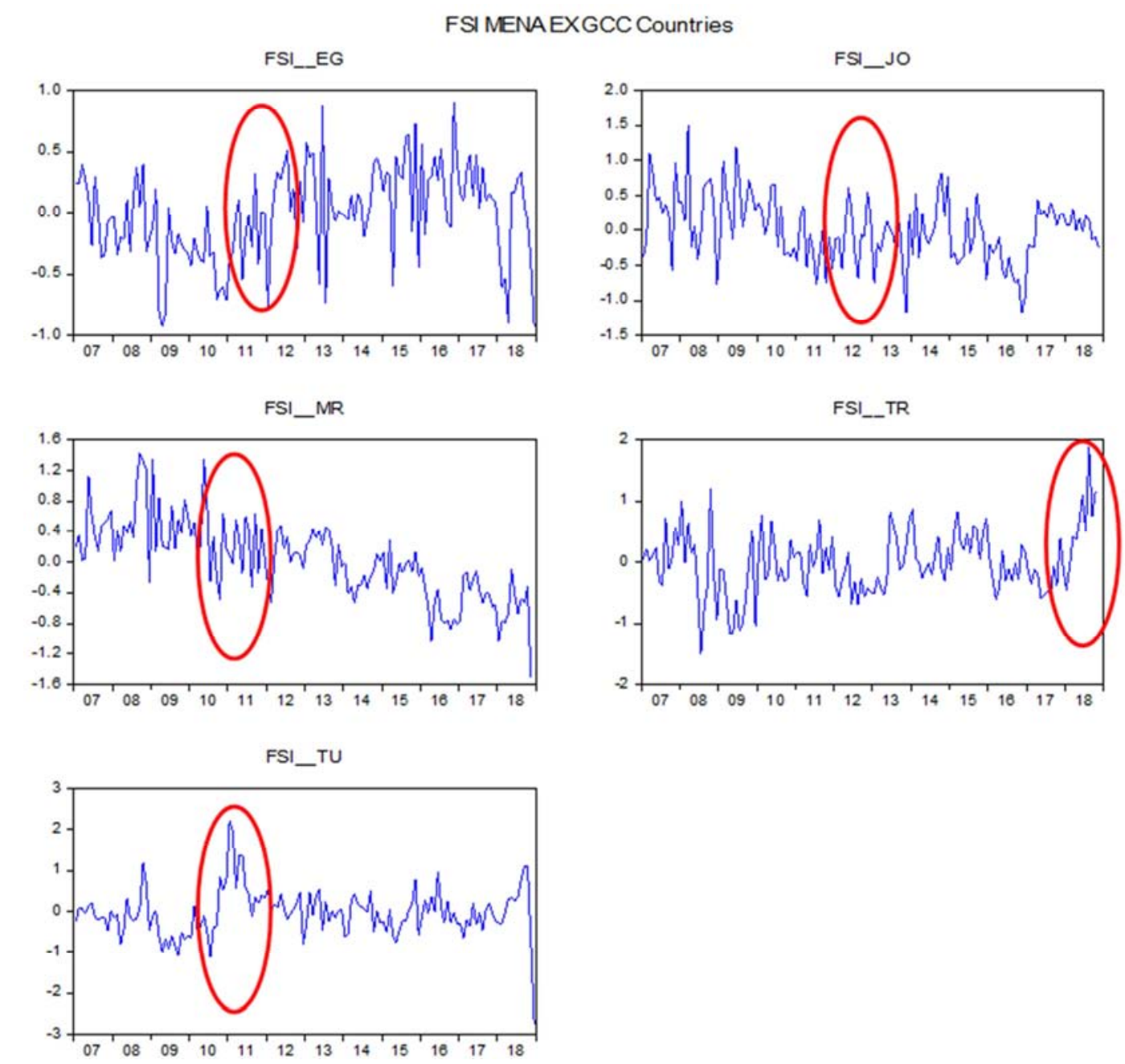

Figure 4. FSI of MENA EX GCC countries from January 2007 to December 2018.

Such protests started in Tunisia in late 2010 and rapidly spread to other Arab countries by early 2011, including Bahrain, Egypt, Morocco, and others. Some dates are an expression of financial stress, as an example, Tunisian revolution ( December17, 2010), Egyptian crisis (January 25, 2011), Peaceful demonstrations in Morocco (January 30,
2011), Turkish coup attempt (2016) and Turkish military operation in Afrin (2018).

Arab countries have experienced a delicate social, political, economic and financial turbulence that is reflected by the aggregated stress index of MENA Ex GCC country. Through exploring the ramifications of the Arab Spring, Acemoglu et 
al. [26] support that the events of the Arab Spring resulted in significantly less efficient financial markets, driving down economic growth at the regional level.

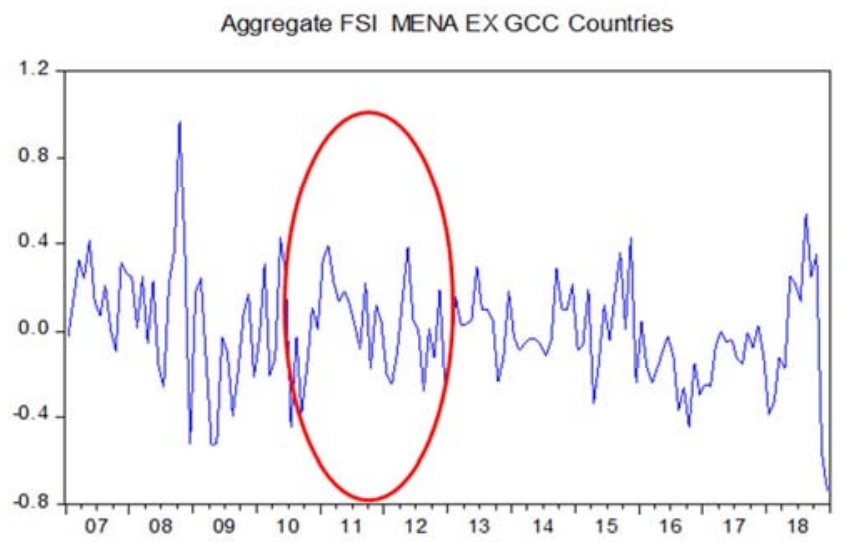

Figure 5. Aggregate FSI of MENA EX GCC countries from January 2007 to December 2018.

\subsection{Descriptive Statistics}

The table below reports descriptive statistics for variables. Panel A presents the statistics of the financial stress index. Panel B relates to stock market index returns. In particular we report, the mean, the standard deviation, the maximum value, the minimum value, the Skewness, the Kurtosis and the Jarque-Bera test of each variable for the MENA financial markets for the period from January 2007 to December 2018.

We note that the stress indices have a large deviation that can be explained by the instability and uncertainty of the financial market. For MENA region, the mean of the Financial Stress Indices are close to zero in all cases and rather small compared to their respective standard deviations. The kurtosis statistic is greater than 3 for all the series except Egypt, suggesting that distributions of all series are leptokurtic (higher peaked around the mean with fatter tails compared to the normal distribution). It is also worth noting that all the series are skewed positively (except some countries).

Table 1. Descriptive statistics of MENA countries.

\begin{tabular}{|c|c|c|c|c|c|c|}
\hline & FSI_BA_ & FSI_KW_ & FSI_OM & FSI_QA & FSI_SA_ & FSI_UAE \\
\hline \multicolumn{7}{|c|}{ Panel A: Financial Stress Index } \\
\hline Mean & 0.001834 & 0.012037 & 0.005557 & 0.003334 & 0.004498 & 0.027462 \\
\hline Max & 2.127634 & 1.467086 & 1.520359 & 2.036376 & 1.983812 & 1.208441 \\
\hline Min & -1.125328 & -1.621931 & -1.592979 & -1.148557 & -1.394526 & -1.667071 \\
\hline St. D & 0.509079 & 0.413145 & 0.468333 & 0.466150 & 0.512698 & 0.426664 \\
\hline $\mathrm{Sk}$ & 1.286080 & -0.026200 & 0.177392 & 0.583366 & -0.052324 & -0.060258 \\
\hline Kur & 6.636805 & 4.965626 & 3.993558 & 5.512955 & 4.631616 & 4.338043 \\
\hline \multicolumn{7}{|c|}{ Panel B: Market Index Return } \\
\hline Mean & -0.003512 & -0.004202 & -0.001773 & 0.008323 & $-9.39 \mathrm{E}-05$ & 0.003429 \\
\hline Max & 0.092475 & 0.172782 & 0.138092 & 0.176594 & 0.178952 & 0.182842 \\
\hline Min & -0.130165 & -0.327963 & -0.313154 & -0.327962 & -0.297753 & -0.180843 \\
\hline St. D & 0.032917 & 0.057067 & 0.051616 & 0.068634 & 0.068700 & 0.054876 \\
\hline $\mathrm{Sk}$ & -0.577148 & -1.875408 & -1.635960 & -1.133647 & -0.635058 & -0.368598 \\
\hline Kur & 5.196907 & 12.56899 & 11.81768 & 7.789408 & 5.350444 & 4.946702 \\
\hline
\end{tabular}

Table 1. Continued.

\begin{tabular}{|c|c|c|c|c|c|}
\hline & FSI_EG_ & FSI_JO_ & FSI_MR & FSI_TU_ & FSI TR \\
\hline \multicolumn{6}{|c|}{ Panel A: Financial Stress Index } \\
\hline Mean & 0.001197 & 0.015319 & 0.045483 & 0.003911 & -0.013701 \\
\hline Max & 0.908149 & 1.498424 & 1.420328 & 2.221040 & 1.884748 \\
\hline Min & -0.931408 & -1.183310 & -1.030964 & -1.116352 & -1.508768 \\
\hline St. D & 0.373954 & 0.475097 & 0.504349 & 0.537472 & 0.522612 \\
\hline Sk & -0.272824 & 0.181158 & 0.323066 & 1.005477 & 0.260700 \\
\hline Kur & 2.767414 & 3.184156 & 3.088541 & 5.437414 & 3.830435 \\
\hline JB & 2.081653 & 0.977350 & 2.516511 & 59.07748 & 5.688759 \\
\hline \multicolumn{6}{|c|}{ Panel B: Market Index Return } \\
\hline Mean & 0.004288 & -0.003171 & 0.001259 & 0.007976 & 0.005884 \\
\hline Max & 0.311688 & 0.103743 & 0.100921 & 0.095492 & 0.205784 \\
\hline Min & -0.403342 & -0.250172 & -0.113643 & -0.142611 & -0.262915 \\
\hline St. D & 0.093161 & 0.038413 & 0.037624 & 0.037680 & 0.075396 \\
\hline $\mathrm{Sk}$ & -0.409595 & -1.738448 & 0.218963 & -0.491790 & -0.436927 \\
\hline Kur & 5.468354 & 14.67710 & 3.346928 & 4.769599 & 4.074951 \\
\hline JB & 40.58307 & 890.6614 & 1.872825 & 24.59346 & 11.51484 \\
\hline
\end{tabular}

Further, we clearly show that Bahrain, Kuwait, Oman, Saudi Arabia and Jordan have a negative mean return and the rest have positive mean returns. The Skewness of stock index returns is negatively signed for all countries except Morocco.

The results also show that the Kurtosis is greater than 3 for 
the two variables suggesting that the distributions are leptokurtic. So we can see that the hypothesis of normality is rejected. The departure of the normality assumption has been statistically confirmed by the Jarque-Bera test manifesting with a high value, which rejects the null hypotheses of normality for all variables; therefore, none of the series are normally distributed.

\subsection{Relationship Between Studied Countries FSI: Covariance and Causality Analysis}

In this part we will discuss the interaction between financial stress indexes in order to highlight the relationship between countries financial stress. Additionally, we perform Granger causality tests. These tests make it possible to know the movement of the volatility of a given stock market precedes that of another market following a random shock on a given market.

For the MENA Ex GCC countries, the co-variances between the FSIs are less important, indicating a weak interconnection between these countries. Of course, even these countries are all part of the MENA region, they are quite heterogeneous with significant structural divergences.

Table 2. Cross-Correlation between FSI in MENA countries.

\begin{tabular}{|c|c|c|c|c|c|c|c|c|c|c|c|}
\hline & FSI EG & FSI TUN & FSI MR & FSI JO & FSI TUR & FSI SA & FSI OM & FSI KW & FSI BA & FSI UAE & FSI QA \\
\hline FSI EG & 1.0000 & & & & & & & & & & \\
\hline FSI TUN & 0.0164 & 1.0000 & & & & & & & & & \\
\hline FSI MR & -0.1100 & -0.0083 & 1.0000 & & & & & & & & \\
\hline FSI JO & -0.0157 & -0.1473 & 0.3382 & 1.0000 & & & & & & & \\
\hline FSI TUR & 0.1389 & 0.2465 & -0.0464 & 0.0364 & 1.0000 & & & & & & \\
\hline FSI SA & 0.1583 & 0.0572 & 0.0209 & 0.1696 & 0.0560 & 1.0000 & & & & & \\
\hline FSI OM & 0.1954 & -0.0077 & -0.0715 & 0.0559 & 0.0256 & 0.1953 & 1.0000 & & & & \\
\hline FSI BA & -0.0196 & 0.0111 & 0.2808 & 0.2232 & 0.0165 & 0.1175 & 0.3292 & 0.2424 & 1.0000 & & \\
\hline FSI UAE & -0.0386 & -0.1569 & 0.1404 & 0.1724 & -0.0986 & 0.4301 & 0.2442 & 0.2568 & 0.4013 & 1.0000 & \\
\hline FSI QA & 0.1488 & 0.1073 & 0.2968 & 0.2977 & 0.1139 & 0.4605 & 0.1799 & 0.2028 & 0.2926 & 0.2650 & 1.0000 \\
\hline
\end{tabular}

Golf Cooperation members are more connected. In fact, the covariance between FSIs in GCC countries is the largest in the MENA region. For example, the covariance between FSI Qatar and FSI Saudi Arabia exceeds 45\%. Also between FSI UAE and FSI Saudi Arabia at the turn of $43 \%$ and between FSI UAE and FSI Bahrain equally is around $40 \%$.

In addition, many ways of granger causality are detected through GCC and MENA Excluding GCC countries.

Figures below provide a double causality way between United Arab Emirates and Oman financial stress index, also between Saudi Arabia and Qatar. It shows also that, for example, Saudi Arabia financial stress index affects United Arab Emirates, Qatar and Bahrain financial stress index.
These are expected results. Indeed, its economies have significant structural and cyclical similarities, for these countries, oil represent the fundamental pillar or even the heart of these economy.

Specifically, we can report a low dependency between the stress indices studied during the full period. Indeed, we find only four links of causality in the sense of Granger. The probabilities related to the Fisher statistic are below the significance thresholds of $5 \%$. This implies the rejection of the null hypothesis and therefore the acceptance of the alternative hypothesis, that is to say, the existence of a causal relation between these indices.
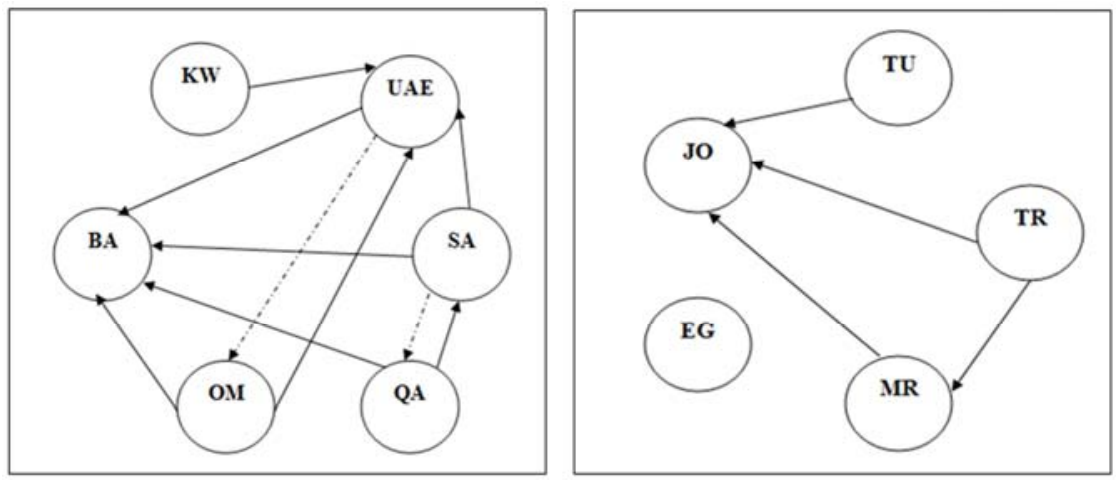

Figure 6. Granger Causality between countries.

\section{The Nexus between Financial Stress Index and Stock Market Return}

In order to study the dynamic relationship between the financial stress index and the stock markets returns, we adopted the VAR (vector auto regression) model (Kim and Doucouliagos [27] and Canarella, Miller and Pollard [28]). In fact, this model is suitable for the analysis of dynamic links between variables since it can identify the main transmission channels and stimulate the responses of share prices in one 
market to innovations in other markets. It has the advantage of being dynamic in the sense that it takes into account the origin of the shocks, their impacts, their amplitudes and their amortization periods. The VAR model has several advantages. First, the variables to be modeled are all stationary. Second, we do not need to specify which the exogenous and endogenous variables are, all are endogenous. Third, they allow variables to depend not only on their history and error term, but also on the past values of other variables. Finally, the number of changes associated with each variable in each equation is identical.

It also allows the examination of impulse response functions, that is, to simulate the responses of a given market to innovations in other markets. The Eun and Shim [29] VAR model used is as follows:

$$
\mathrm{Y}(\mathrm{t})=\mathrm{C}+\sum_{S=1}^{m} A(s) Y(t-s)+e(t)
$$

Where:

$\mathrm{Y}(\mathrm{t})$ : Column vector $K \times 1(K=2)$

C: Column vector $(K \times 1)$ of constants

A (s): Coefficients matrix $(K \times K)$

m: Delay length

$$
\begin{aligned}
& \text { e }(\mathrm{t}) \text { : Column vector }(K \times 1) \text { of résiduals } \\
& \left\{\begin{array}{c}
E(e(t))=0 \\
\left(e(t) e^{\prime}(t-s)\right)=0 ; \forall s \neq 0 \\
E\left(e(t) e^{\prime}(t)\right)=\Omega
\end{array}\right.
\end{aligned}
$$

With: $\Omega=\left\{\sigma_{i j}, i, j=1,2 \ldots, K\right\}$ : Positive size matrix $(K \times K)$

Equation (4) can be written as follows:

$$
Y(t)=\mu+\sum_{s=0}^{\infty} B(s) e(t-s)
$$

Where: $\mu$ : Column vector $(K \times 1)$ constants

$B(s)$ : Matrix of coefficients $(K \times K)$

The $i j^{t h}$ component of $B(s)$ indicates the response of block $i$, after speriods, following a random shock on block $j$.

The impulse response function makes it possible to measure the effect of a shock linked to the evolution of a stress index (at time $t$ ) on the other indices (at time $t+$ $n ; \mathrm{n}=0,1,2 \ldots)$. Given that the components of $e(t)$ can be correlated, the error term can be transformed otherwise. The traditional approach of Sim (1980) uses the Cholesky decomposition of $\Omega$ in order to orthogonalize the residuals.

Let $V$ be a triangular matrix of size $\left(K \times K^{\prime}\right)$ such that $\mathrm{W}^{\prime}=\Omega$. The equation (5) can be presented in the following form:

$$
\begin{gathered}
Y(t)=\mu+\sum_{s=0}^{\infty} C(s) \xi(t-s) \\
C(S)=B(s) V \\
\xi(t-s)=V^{-1} e(t-s): \text { Orthogonalized residuals vector } \\
\mathrm{E}\left(\xi(\mathrm{t}) \xi\left(\mathrm{t}^{\prime}\right)\right)=I_{K}
\end{gathered}
$$

The column vector $(K \times 1)$ of the orthogonalized impulse response function relating to a shock on the element $j$, of stock returns $Y(t+n)$ is given by:

$$
\psi_{0}^{j}=\mathrm{C}(\mathrm{n}) \varepsilon \mathrm{j}, \mathrm{n}=0,1,2, \ldots
$$

$\varepsilon_{j}:$ Vector $(\mathrm{K} \times 1)$ which takes the value 1 in element $\mathrm{n}^{\circ} \mathrm{j}$ and 0 elsewhere.

\subsection{Estimation VAR: Results and Interpretation}

Before estimating the VAR model, make sure that the variables used are stationary. To verify the presence of unit root or not, we use the ADF (Augmented Dickey and Fuller) and PP (Phillips Perron) tests.

\subsubsection{Unit Root Test}

The stationarity of the series is examined using the ADF and PP unit root test. ADF tests were performed under the three possible specifications of the model, namely with constant, with constant and trend, and without constant and without trend.

The decision rule attests that if the ADF or PP value is less than the critical value, then we reject the null hypothesis of the presence of a unit root and we accept the alternative stationarity hypothesis of the series. Otherwise, we accept the non-stationarity hypothesis of the series. The results are summarized in the following table:

Table 3. Unit root test.

\begin{tabular}{llllll}
\hline \multirow{2}{*}{ Variables } & ADF & & PP & & Cr. Value 5\% \\
\cline { 2 - 5 } & T-statistic & Cr. Value 5\% & T-statistic & -2.863173 & I(0) \\
\hline FSI & -14.00901 & -2.863176 & -28.95818 & -2.863173 \\
RET & -33.59326 & -2.863173 & -33.65006 & I(0) \\
\hline
\end{tabular}

The table shows that the statistical value of the ADF test associated with the different variables is greater than the critical value at the 5\% threshold. Following the ADF and PP test decision rule stated above, these results lead us to reject the null hypothesis of the presence of a unit root. We can then deduce that all the variables are stationary at level.

\subsubsection{VAR Model Estimation}

In order to carry out our study, we will use VAR modeling.
The use of a VAR model is methodically justified by the fact that VAR models allow simulations making it possible to capture the modifications of the objective variables following a shock on the instrument variables. VAR models have three advantages: first, they make it possible to explain a variable in relation to its lags and according to the information contained in other relevant variables, which raises cointegration problems, second, we have a very large information space and finally, this method is quite simple to implement and includes estimation procedures and tests. 
VAR models must be estimated from stationary series. It is a property of invariance of the statistical characteristics of the processes for all the translations in time. It is impossible to identify a process if all of its characteristics change over time. The results of the estimation of the autoregressive vector are presented in table below:

Table 4. VAR estimation of the financial stress index and stock return index relationship of MENA countries.

\begin{tabular}{|c|c|c|c|c|c|c|c|c|c|c|c|}
\hline \multicolumn{12}{|c|}{ Panel A: GCC Countries } \\
\hline & \multicolumn{4}{|l|}{ Bahrain } & \multicolumn{4}{|c|}{ Kuwait } & \multicolumn{3}{|l|}{ Oman } \\
\hline & \multicolumn{2}{|l|}{ FSI } & \multicolumn{2}{|l|}{ RET } & \multicolumn{2}{|l|}{ FSI } & \multicolumn{2}{|l|}{ RET } & FSI & \multicolumn{2}{|c|}{ RET } \\
\hline FSI (-1) & \multicolumn{2}{|c|}{$0.547 * * *[6.381]$} & \multicolumn{2}{|c|}{$-0.035 * * *[-7.047]$} & \multicolumn{2}{|c|}{$0.434 * * *[5.152]$} & \multicolumn{2}{|c|}{$-0.0009 * * *[-0.070]$} & $0.329 * * *[3.349]$ & \multicolumn{2}{|c|}{$0.001 * *[0.171]$} \\
\hline FSI (-2) & \multicolumn{2}{|c|}{$0.126 *[1.224]$} & \multicolumn{2}{|c|}{$0.002 * *[0.487]$} & \multicolumn{2}{|c|}{$0.168 * *[2.172]$} & \multicolumn{2}{|c|}{$0.026 * *[2.137]$} & $0.254 * * *[2.564]$ & \multicolumn{2}{|c|}{$-0.008[-0.781]$} \\
\hline $\operatorname{RET}(-1)$ & \multicolumn{2}{|c|}{$0.258[0.180]$} & \multicolumn{2}{|c|}{$0.231 * * *[2.735]$} & \multicolumn{2}{|c|}{$-3.674 * * *[-6.852]$} & \multicolumn{2}{|c|}{$0.359 * * *[4.252]$} & $1.542 *[1.784]$ & \multicolumn{2}{|c|}{$0.195 * *[1.990]$} \\
\hline RET (-2) & \multicolumn{2}{|c|}{$0.257[0.215]$} & \multicolumn{2}{|l|}{$0.087[1.230]$} & \multicolumn{2}{|c|}{$1.560 * * *[2.593]$} & \multicolumn{2}{|c|}{$-0.0001[-0.001]$} & $-0.491[-0.559]$ & \multicolumn{2}{|c|}{$0.249 * * *[2.504]$} \\
\hline Panel A: & CC Countri & & & & & & & & & & \\
\hline & Qatar & & & & Sau & Arabia & & & United Arab Em & rates & \\
\hline & FSI & & RET & & FSI & & RET & & FSI & RET & \\
\hline FSI (-1) & $0.264 * * *$ & $2.564]$ & $0.031 * *[1.96$ & & 0.47 & $* *[5.355]$ & $-0.042 *$ & $-3.113]$ & $0.281 * * *[2.987]$ & -0.02 & $*[-1.688]$ \\
\hline FSI (-2) & $0.215 * *$ & 080] & $-0.031 * *[-1.9$ & & 0.21 & $* *[2.383]$ & $0.024 *$ & & $0.308 * * *[3.233]$ & -0.00 & {$[-0.473]$} \\
\hline RET (-1) & $0.324[0$. & & $0.281 * * *$ & & 1.41 & $* *[2.486]$ & $0.030[($ & & $-0.142[-0.200]$ & 0.082 & $.890]$ \\
\hline $\operatorname{RET}(-2)$ & $1.240 *[1$ & 69] & $-0.143[-1.411$ & & 1.18 & $*[2.057]$ & 0.106[ & & $1.396 * *[1.974]$ & 0.137 & $.485]$ \\
\hline Panel B: I & NA Excluc & g GCC C & ntries & & & & & & & & \\
\hline & Egypt & & Jordan & & & Morocco & & Tunisia & & Turkey & \\
\hline & FSI & RET & FSI & & & FSI & RET & FSI & RET & FSI & RET \\
\hline FSI (-1) & $\begin{array}{l}0.265 * * * \\
{[3.354]}\end{array}$ & $\begin{array}{l}0.027 \\
{[0.522]}\end{array}$ & $\begin{array}{l}0.288 * * \\
{[2.999]}\end{array}$ & & & $\begin{array}{l}0.437 * * * \\
{[4.363]}\end{array}$ & $\begin{array}{l}0.007 \\
{[0.749]}\end{array}$ & $\begin{array}{l}0.790 * * * \\
{[6.792]}\end{array}$ & $\begin{array}{l}-0.023 * \\
{[-2.599]}\end{array}$ & $\begin{array}{l}0.596 * * * \\
{[4.451]}\end{array}$ & $\begin{array}{l}-0.017 \\
{[-0.790]}\end{array}$ \\
\hline FSI (-2) & $\begin{array}{l}0.330 * * * \\
{[4.236]}\end{array}$ & $\begin{array}{l}0.009 \\
{[0.173]}\end{array}$ & $\begin{array}{l}0.267 * * \\
{[2.792]}\end{array}$ & & & $\begin{array}{l}0.437 * * * \\
{[4.370}\end{array}$ & $\begin{array}{l}-0.011 \\
{[-1.116]}\end{array}$ & $\begin{array}{l}0.080 \\
{[0.675]}\end{array}$ & $\begin{array}{l}0.006 \\
{[0.649]}\end{array}$ & $\begin{array}{l}0.110 \\
{[0.822]}\end{array}$ & $\begin{array}{l}0.020 \\
{[0.910]}\end{array}$ \\
\hline RET (-1) & $\begin{array}{l}-0.769 * * * \\
{[-2.582]}\end{array}$ & $\begin{array}{l}0.191 \\
{[0.957]}\end{array}$ & $\begin{array}{l}0.315 \\
{[0.267]}\end{array}$ & & & $\begin{array}{l}1.954 * \\
{[1.914]}\end{array}$ & $\begin{array}{l}0.123 \\
{[1.197]}\end{array}$ & $\begin{array}{l}4.895 * * * \\
{[3.494]}\end{array}$ & $\begin{array}{l}-0.075 \\
{[-0.699]}\end{array}$ & $\begin{array}{l}1.552 * * \\
{[1.940]}\end{array}$ & $\begin{array}{l}-0.069 \\
{[-0.521]}\end{array}$ \\
\hline $\operatorname{RET}(-2)$ & $\begin{array}{l}0.944 * * * \\
{[3.113]}\end{array}$ & $\begin{array}{l}-0.012 \\
{[-0.058]}\end{array}$ & $\begin{array}{l}3.655 * * * \\
{[3.121]}\end{array}$ & & $\begin{array}{l}1 * * * \\
18]\end{array}$ & $\begin{array}{l}-0.012^{*} \\
{[-0.389]}\end{array}$ & $\begin{array}{l}0.0004 \\
{[0.147]}\end{array}$ & $\begin{array}{l}-0.072 \\
{[-1.728]}\end{array}$ & $\begin{array}{l}0.007 \\
{[2.328]}\end{array}$ & $\begin{array}{l}0.633 \\
{[0.845]}\end{array}$ & $\begin{array}{l}0.120 \\
{[0.960]}\end{array}$ \\
\hline
\end{tabular}

Notes: Terms between [] represent $t$-Satistics. ${ }^{*}, * * * *$ respectively represent significance at the $10 \%, 5 \%$ and $1 \%$ level

Note that the majority of values are significant. What interests us in fact in this estimation of the VAR (2) model is to express the return as a function of financial stress. The results indicate that the performance of the stock indices depends positively on its past except Tunisia and Turkey, which is explained by the upward trend in the performance of the indices. It depends negatively on the evolution of the financial stress index shifted by one period for the case of Tunisia, Kuwait and UAE, which affirms and reinforces our supposition.

Also, the stress index positively depends on his past delayed either by one or two periods. This last result can be better explained using the impulse response functions.

\subsection{Impulse Response Functions}

Impulse analysis will be used to determine the influence of a shock related to the evolution of a given stress index on the returns of different financial markets. The graphs, presented below, depict the effect of a financial shock expressed through a stress index on the performance of financial markets for a maximum horizon of 10 months. Thus, from a shock on a given index, the impulse response function makes it possible to determine the amplitude and duration of the response of the other indices.
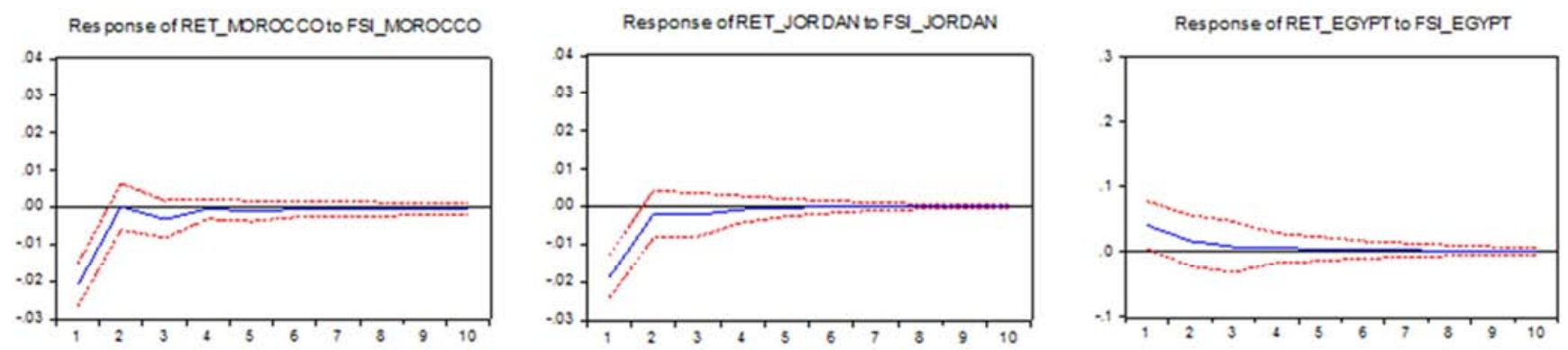

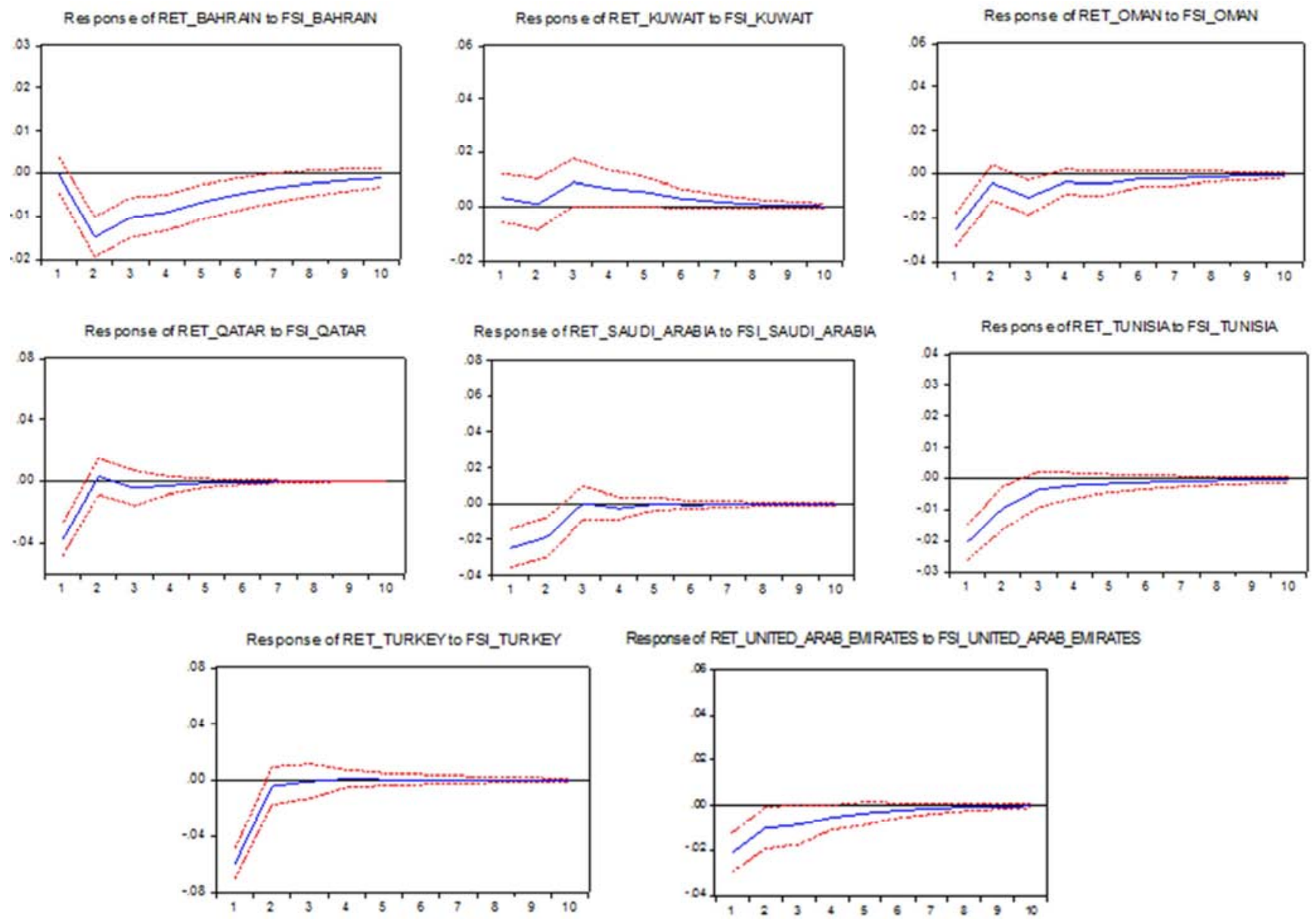

Response of RET_UNIED_ARAB_EMRATES D FSIUNITED_ARAB_EMRATES

Figure 7. Impulse response functions: RETURN to FSI.

In this part, we will present the different results of the VAR model specified in the previous parts. We will focus on shock response functions which make possible to synthesize the essential of the information contained in the dynamics of the estimated VAR system. The following figures retrace the impulse response functions; the dotted curves representing the confidence interval (see graphs). We consider that the amplitude of the shock is equal to twice the standard deviation and we are interested in the effects of the shock over 10 periods (that is to say 10 months). This horizon represents the time required for the variables to return to their long-term levels.
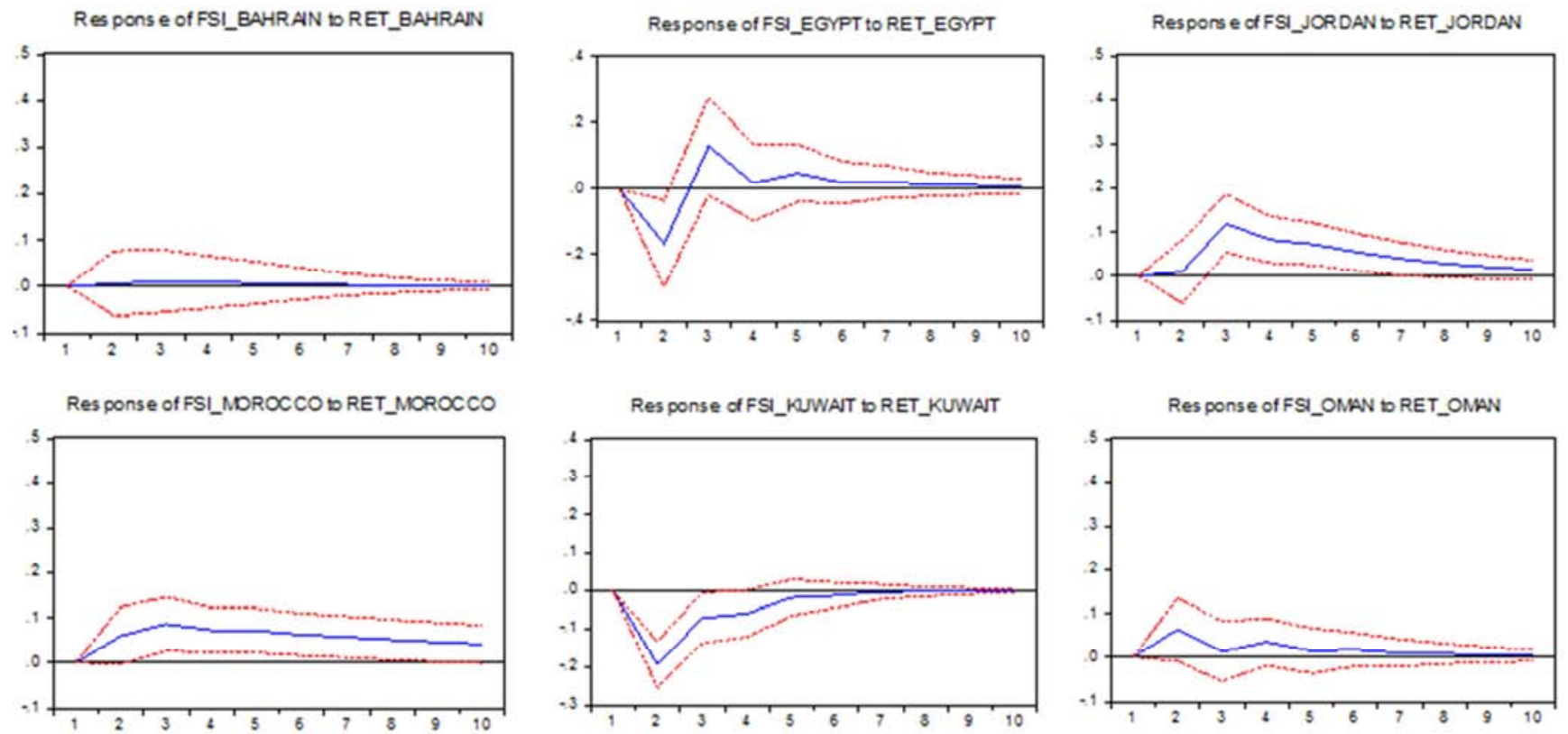


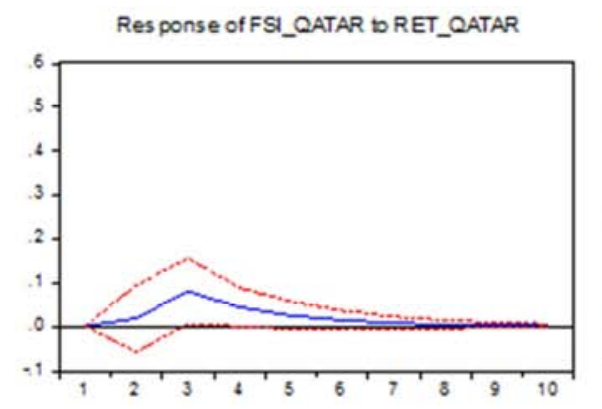

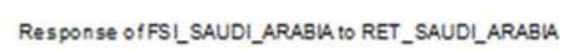
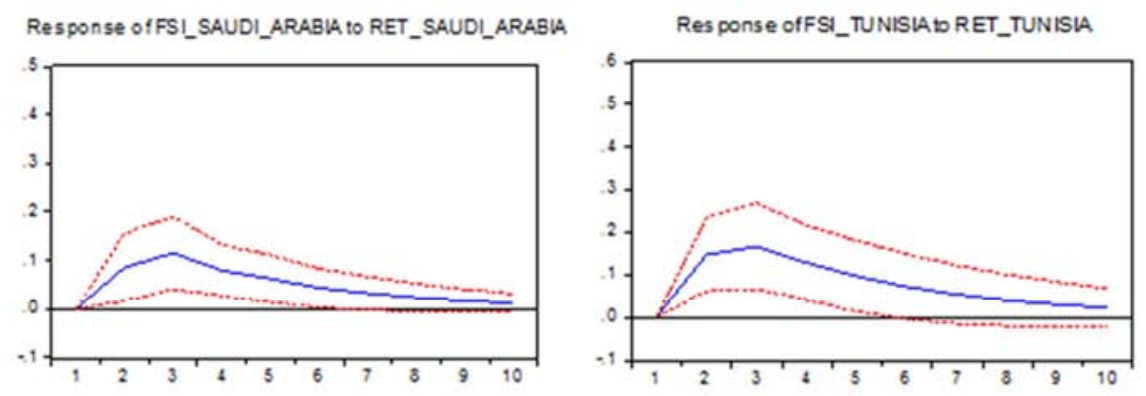
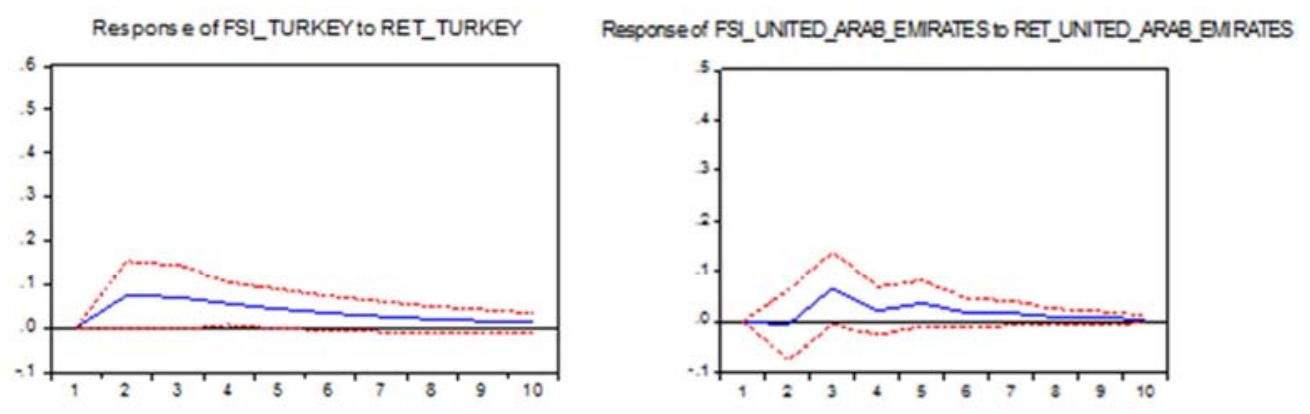

Figure 8. Impulse response functions: FSI to RETURN.

The charts above represent the responses of stock market index returns (Figure 7), stimulating a shock respectively on financial stress indexes. Several remarks can be observed:

A shock in the markets of the GCC region affects practically the other markets. However, this shock will be quickly absorbed, that is to say that there is no phenomenon of persistence of shocks such is the example, of Saudi Arabia, Oman, Qatar, UAE being part of the Gulf Cooperation Council and Jordan, Morocco, Tunisia and Turkey representing MENA countries excluding GCC react to shocks. In fact, the magnitude of the shock is higher for the case of Bahrain during the crisis period.

Nevertheless, following a shock in the GCC region, the Kuwait market is the only one which reacts more. Also for Egypt where his behavior was practically stable.

Regarding the impulse response functions of FSI for stock return shocks (Figure 8), we can denote that most markets react to shocks in the two sub-regions. With the exception of the shock on the Bahrain market where the reaction is actually been stable.

In addition, the charts show us that the response of indices to a shock in the markets is relatively weak and hardly increases over the rest of the period. This confirms the independence of such a market from other international stock markets namely Egypt, Morocco and Turkey.

As a conclusion, a positive shock on the financial stress index translates into a negative effect on stock market performance during the first year. This effect then disappears in slow motion before finding its long-term level.

\section{Conclusion}

In this research, we have constructed financial stress indices for the MENA countries financial system by using the variance - equal weighting methods. The FSIs are monthly indexes, which try to evaluate the state of instability in the financial system. In fact, financial stress that get started in advance economies passed rapidly and strongly to developing and emerging economies. Besides, graphical examination of the indexes reveals that the extreme values of the FSIs are generally connected with well-known past financial stress episodes like the well known Great Recession, the Arab Spring, the Oil Crisis and others...

Additionally, the financial markets in the Middle East and North Africa have suffered many crises, such as political crises, social crises and oil crises. In fact, due to the impact of the subprime mortgage crisis (2007-2009) and the Arab Spring (late 2010-2012), these financial market indexes experienced a very significant decline. The political unrest observed after the outbreak of the Arab Revolution had a major impact on the financial markets in the Middle East and North Africa. The negative impact of the oil crisis (20142015), accompanied by a sharp drop in oil prices, not only reduced its own investment expenditures, but also reduced the investment expenditures of other Arab countries, thus severely hitting manyoil exporting MENA countries. Furthermore, in order to study the dynamic relationship between the financial stress index and the stock markets returns, we adopted the VAR model and impulse response functions.

We showed that the performance of the stock indices depends positively on its past and also, the stress index positively depends on his past delayed either by one or two periods. Finally, the study of impulse response functionsshows that a positive shock on the financial stress index translates into a negative effect on stock market performance during the first year. This effect then disappears in slow motion before finding its long-term level. 


\section{References}

[1] Reinhart, C. M., \& Rogoff, K. S. (2014). Recovery from financial crises: Evidence from 100 episodes. American Economic Review, 104 (5), 50-55.

[2] Polat, O., \& Ozkan, I. (2019). Transmission mechanisms of financial stress into economic activity in Turkey. Journal of Policy Modeling, 41 (2), 395-415.

[3] Illing, M., \& Liu, Y. (2006). Measuring financial stress in a developed country: An application to Canada. Journal of Financial Stability, 2 (3), 243-265.

[4] Hakkio, C. S., \& Keeton, W. R. (2009). Financial stress: what is it, how can it be measured, and why does it matter? Economic Review, 94 (2), 5-50.

[5] Balakrishnan, R., Danninger, S., Elekdag, S., \& Tytell, I. (2011). The transmission of financial stress from advanced to emerging economies. Emerging Markets Finance and Trade, 47 (sup2), 40-68.

[6] Cevik, E. I., Dibooglu, S., \& Kutan, A. M. (2013a). Measuring financial stress in transition economies. Journal of financial stability, 9 (4), 597-611.

[7] Cardarelli, R., Elekdag, S., \& Lall, S. (2011). Financial stress and economic contractions. Journal of Financial Stability, 7 (2), 78-97.

[8] Louzis, D. P., \& Vouldis, A. T. (2013). A financial systemic stress index for Greece.

[9] Cevik, E. I., Dibooglu, S., \& Kenc, T. (2013b). Measuring financial stress in Turkey. Journal of Policy Modeling, 35 (2), 370-383.

[10] Dahalan, J., Abdullah, H. B., \& Umar, M. (2016). Measuring financial stress index for Malaysian economy. International Journal of Economics and Financial Issues, 6 (3).

[11] Duprey, T., Klaus, B., \& Peltonen, T. (2017). Dating systemic financial stress episodes in the EU countries. Journal of Financial Stability, 32, 30-56.

[12] El-Shal, A. (2012, December). The spillover effects of the global financial crisis on economic activity in emerging economies-investigating the Egyptian case using the financial stress index. In Economic Research Forum Working Papers (No. 737).

[13] Cevik, E. I., Dibooglu, S., \& Kenc, T. (2016). Financial stress and economic activity in some emerging Asian economies. Research in International Business and Finance, 36, 127-139.

[14] Tng, B. H., Kwek, K. T., \& Sheng, A. (2012). Financial stress in ASEAN-5 economies from the Asian crisis to the global crisis. The Singapore Economic Review, 57 (02), 1250013.

[15] Ekinci, A. (2013). Financial stress index for Turkey. Doğuş Üniversitesi Dergisi, 14 (2), 213-229.
[16] Duca, M. L., \& Peltonen, T. A. (2013). Assessing systemic risks and predicting systemic events. Journal of Banking \& Finance, 37 (7), 2183-2195.

[17] Zigraiova, D., \& Jakubik, P. (2015). Systemic event prediction by an aggregate early warning system: An application to the Czech Republic. Economic Systems, 39 (4), 553-576.

[18] Park, C. Y., \& Mercado Jr, R. V. (2014). Determinants of financial stress in emerging market economies. Journal of Banking \& Finance, 45, 199-224.

[19] Baxa, J., Horváth, R., \& Vašíček, B. (2013). Time-varying monetary-policy rules and financial stress: Does financial instability matter for monetary policy?. Journal of Financial Stability, 9 (1), 117-138.

[20] Yiu, M. S., Ho, W. Y. A., \& Jin, L. (2010). A measure of financial stress in Hong Kong financial market-the financial stress index. Hong Kong Monetary Authority Research Note, 2, 2010 .

[21] Rey, H., (2009). Discussion of How Linkages Fuel the Fire. http://www.internationalgrowthcentre.org/index.php?q=node/3 76.

[22] Holló, D., Kremer, M. \& Duca, M. (2012). CISS - A Composite Indicator of Systemic Stress in the Financial Sector ECB Working Paper Series, No. 1426.

[23] Balakrishnan R., Danninger S, Elekdag S., and Tytell I. (2009). "The Transmission of Financial Stress from Advanced to Emerging Economies", IMF Working Papers /09/133, June 2009.

[24] MacDonald, R., Sogiakas, V., \& Tsopanakis, A. (2018). Volatility co-movements and spillover effects within the Eurozone economies: A multivariate GARCH approach using the financial stress index. Journal of International Financial Markets, Institutions and Money, 52, 17-36.

[25] Kaminsky, G. L., \& Reinhart, C. M. (1999). The twin crises: the causes of banking and balance-of-payments problems. American economic review, 89 (3), 473-500.

[26] Acemoglu, D., Hassan, T. A., \& Tahoun, A. (2018). The power of the street: Evidence from Egypt's Arab Spring. The Review of Financial Studies, 31 (1), 1-42.

[27] Kim, J. H., \& Doucouliagos, H. (2005). Realized volatility and correlation in grain futures markets: Testing for spill-over effects. Available at SSRN 791264.

[28] Canarella, G., Miller, S. M., \& Pollard, S. K. (2009). Dynamic stock market interactions between the Canadian, Mexican, and the United States markets: The NAFTA experience. Nova Science Publishers, Inc., $4^{\text {th }}$ Quarter.

[29] Eun, C. S., \& Shim, S. (1989). International transmission of stock market movements. Journal of financial and quantitative Analysis, 24 (2), 241-256. 